\title{
What Should We Tell Our Patients? Lifetime Guarantee or is it 5- to 10-year Warranty on a Parathyroidectomy for Primary Hyperparathyroidism?
}

\author{
Janice L. Pasieka ${ }^{1}$
}

Published online: 25 March 2015

(c) Société Internationale de Chirurgie 2015

In the endocrine surgical world, a new debate has emerged-that being which operation is the best for sporadic primary hyperparathyroidism (HPT). Advances in technology, preoperative imaging, and intra-operative adjuncts have expanded the operative choices for our patients $[1,2]$. No longer is it a mandatory 4-gland bilateral parathyroid exploration as it was in the days of Oliver Cope [3]. Today, with appropriate patient selection, surgeons are successfully utilizing a more focused approach such as imaged-directed or unilateral explorations in order to avoid a bilateral exploration and the additional risks [4-6]. However, recent data have emerged that 10-year cure rates following a focused approach may be lower than bilateral exploration [7, 8]. It has been long recognized that if one looks at all the glands at the initial operation, more histological abnormal glands are found [9]. Siperstein et al. found unrecognized multi-gland disease $16 \%$ of the time when they proceeded to a 4-gland exploration following a 'successful' focused parathyroidectomy [10]. That, along with the fact that the now-recognized incidence of elevated PTH with normal calcium levels following parathyroid surgery (a potential harbinger for recurrence) appears to be higher following a focused approach compared to a bilateral exploration [11-13], has at least caused me to pause and reflect on which operation for sporadic HPT is the best. I attempted to bring about some reflection among the audience on this very topic at the 2014 Asian Association of Endocrine Surgeons meeting in Sri Lanka. I presented data

Janice L. Pasieka

Janice.pasieka@albertahealthservices.ca

1 Department of Surgery, Foothills Medical Center, Calgary, Canada demonstrating a long-term recurrence rate of 4-6\% with a focused approach compared to 1-2 \% with a bilateral operation [7, 8]. Yet given over $80 \%$ of patients with sporadic HPT have solitary adenomas, clearly the majority do achieve a life-long cure from a focused approach. I concluded my talk by stating that parathyroid surgeons need to reflect on the how far the pendulum has swung away from the gold-standard operation. A focused approach may not provide as robust long-term cure as the bilateral operation does, but it clearly has many advantages and should not be totally abandoned as some have advocated [8]. Since access to advanced preoperative imaging and adjuncts like intra-operative PTH (iPTH) are not always possible or have proven not to be cost-effective in some surgical units, many surgeons are providing an operative strategy that best suits their patients within their local healthcare environment and this is not wrong. We have to recognize that what works for one unit may not be the best strategy for another. Surgeons need to define their 'go to operation' and how successful it has been both in short- and long-term followup. When I sat down, the senior author of the Norlen paper (LD) leaned over and asked me "why do we endocrine surgeons feel the need to give a lifetime guarantee to our operations? The orthopedic surgeons give a 5-10 year warranty on the joints they replace and that is still considered a success.'

I have been reflecting on that provocative statement ever since. I believe our need to provide a lifetime guarantee of our work comes from our general surgical background. It is true that we guarantee no further attacks of biliary colic or appendicitis once we perform a cholecystectomy or appendectomy. Yet in our oncology work, we rarely provide a lifetime warrantee for disease-free survival at the time of informed consent. So instead of debating which 
parathyroid operation has superiority, we should instead be addressing which patients are at risk for persistent disease (an operative failure), which patients are at risk for longterm recurrence, and which patients would be well served with an operation that will likely last for the next 10 years. To that end, many investigators have tried to stratify patients at risk for persistent disease following a focused parathyroidectomy by utilizing peri-operative data such as the weight of the resected adenoma, the decline curve of the iPTH measurement, a rebound effect of iPTH, and/or the assessment of the ipsilateral gland [14-17].

The North Shore Unit has utilized their extensive database to retrospectively define those patients at risk for persistent disease following their operative approach to localized sporadic HPT (an image-directed parathyroidectomy without iPTH). They found that the weight of a resected gland of less than $200 \mathrm{mg}$ was associated with a $6 \%$ persistent rate compared to $2 \%$. For them, the overall risk of persistent disease of $3 \%$ is acceptable and explained to the patients preoperatively. Their review identified a group of patients at risk for persistent disease (adenomas $<200 \mathrm{mg}$ ), and as such, a more extensive follow-up program for those at-risk patients could be instituted. McCoy and the Pittsburgh unit utilized both the gland weights and the iPTH values to help decrease the risk of persistent disease by triggering a bilateral exploration at the time of the initial operation [17]. Both strategies work as long as the patient accepts the risk of a second operation versus the risk of a bilateral procedure.

The real question remains-what is the warranty on a parathyroid operation? Should it come with a lifetime guarantee? Is a 10-year warranty following a focus parathyroidectomy in an 84-year-old patient a better approach than a bilateral exploration? These are questions that the surgeon and the patient have to address. There is no single correct answer. Recognizing that a focal approach to sporadic HPT may not have the same durability as a bilateral approach, it will, however, provide normocalcemia in over $90 \%$ of patients for up to 10 years. This should be part of the surgeons' thought processes when discussing the operative management with the patient. The ideal operation for sporadic HPT in my opinion is one that renders the patient normocalcemic for the duration of their life span with minimal operative risk. How this is achieved will depend on the health resources, local expertise, and both the patients' and surgeons' willingness to accept the persistent and recurrence rates for such an approach. Performing a bilateral exploration or utilizing peri-operative information during a focused approach both can achieve the goal of providing best operation for that patient.

\section{References}

1. Lew JI, Solorzano CC (2009) Surgical management of primary hyperparathyroidism: state of the art. Surg Clin North Am 89:1205-1225

2. Mihai R, Barczynski M, Iacobone M, Sitges-Serra A (2009) Surgical strategy for sporadic primary hyperparathyroidism an evidence-based approach to surgical strategy, patient selection, surgical access, and reoperations. Langenbecks Arch Surg. 394:785-798

3. Cope O (1966) The story of hyperparathyroidism at the Massachusetts General Hospital. N Engl J Med 274:1174-1182

4. Udelsman R, Lin Z, Donovan P (2011) The superiority of minimally invasive parathyroidectomy based on 1650 consecutive patients with primary hyperparathyroidism. Ann Surg 253:585-591

5. Russell C (2004) Unilateral neck exploration for primary hyperparathyroidism. Surg Clin North Am 84:705-716

6. Bergenfelz A, Kanngiesser V, Zielke A, Nies C, Rothmund M (2005) Conventional bilateral cervical exploration versus open minimally invasive parathyroidectomy under local anaesthesia for primary hyperparathyroidism. Br J Surg 92:190-197

7. Schneider DF, Mazeh H, Sippel RS, Chen H (2012) Is minimally invasive parathyroidectomy associated with greater recurrence compared to bilateral exploration? Analysis of more than 1,000 cases. Surgery 152:1008-1015

8. Norman J, Lopez J, Politz D (2012) Abandoning unilateral parathyroidectomy: why we reversed our position after 15,000 parathyroid operations. J Am Coll Surg 214:260-269

9. McGill J, Sturgeon C, Kaplan SP, Chiu B, Kaplan EL, Angelos P (2008) How does the operative strategy for primary hyperparathyroidism impact the findings and cure rate? A comparison of 800 parathyroidectomies. J Am Coll Surg 207:246-249

10. Siperstein A, Berber E, Barbosa GF et al (2008) Predicting the success of limited exploration for primary hyperparathyroidism using ultrasound, sestamibi, and intraoperative parathyroid hormone: analysis of 1158 cases. Ann Surg 248:420-428

11. Carsello CB, Yen TW, Wang TS (2012) Persistent elevation in serum parathyroid hormone levels in normocalcemic patients after parathyroidectomy: does it matter? Surgery 152:575-583

12. Stuart HC, Harvey A, Pasieka JL (2014) Normocalcemic hyperparathyroidism: preoperatively a disease, postoperatively cured? Am J Surg 207:673-680 (discussion 680-681)

13. Goldfarb M, Gondek S, Irvin GLR, Lew JI (2011) Normocalcemic parathormone elevation after successful parathyroidectomy: long-term analysis of parathormone variations over 10 years. Surgery 150:1076-1084

14. Udelsman R, Donovan P, Shaw C (2014) Cure predictability during parathyroidectomy. World J Surg 38:525-533. doi:10. 1007/s00268-013-2327-8

15. Bergenfelz AO, Jansson SK, Wallin GK et al (2009) Impact of modern techniques on short-term outcome after surgery for primary hyperparathyroidism: a multicenter study comprising 2,708 patients. Langenbecks Arch Surg. 394:851-860

16. Schneider DF, Ojomo KA, Mazeh H, Oltmann SC, Sippel RS, Chen H (2013) Significance of rebounding parathyroid hormone levels during parathyroidectomy. J Surg Res 184:265-268

17. McCoy KL, Chan NH, Armstrong MJ et al (2014) The small abnormal parathyroid gland is increasingly common and heralds operative complexity. World J Surg 38:1274-1281. doi:10.1007/ s00268-014-2450-1 